\title{
Activity and Diet of Bats in Conventional versus Organic Apple Orchards in Southern Michigan
}

\author{
BrenNA L. LONG ${ }^{1}$ AND ALLEN KuRTA ${ }^{1,2}$ \\ ${ }^{1}$ Department of Biology, Eastern Michigan University, Ypsilanti, Michigan 48197 USA \\ ${ }^{2}$ Corresponding author: akurta@emich.edu
}

Long, Brenna L., and Allen Kurta. 2014. Activity and diet of bats in conventional versus organic apple orchards in southern Michigan. Canadian Field-Naturalist 128(2): 158-164.

Organic farming practices have been suggested as a conservation strategy that can provide productive foraging sites for insectivorous bats in agricultural areas. We tested the hypothesis that the number and diversity of insects captured and the resulting activity and diet of bats would differ between organic and conventional apple orchards. During the summer of 2009 and 2010, we captured 131 Big Brown Bats (Eptesicus fuscus) and five Eastern Red Bats (Lasiurus borealis) by mist netting in four organic and four conventional orchards in Michigan. Acoustic monitoring revealed that most calls $(59 \%)$ were produced by Big Brown Bats, followed by Hoary Bats (L. cinereus), Eastern Red Bats, and unidentified species of Myotis. Most insects (96\%) captured in light traps were Coleoptera, Diptera, Hemiptera, Lepidoptera, and Trichoptera; fecal analysis indicated that Coleoptera dominated the diet of Big Brown Bats ( $79 \%$ by volume), followed by Diptera (14\%). There were no significant differences between organic and conventional orchards in number of insects captured with light traps, bats captured with mist nets, acoustic recordings of bats, or proportion of Coleoptera and Diptera consumed by the bats. However, the taxonomic composition of captured insects and acoustic recordings was not homogenous among orchards in either group, suggesting that factors other than farming practices were more important in determining which insects and bats were found in the small orchards typical of southern Michigan.

Key Words: Big Brown Bat; Eptesicus fuscus; Eastern Red Bat; Lasiurus borealis; Hoary Bat; Lasiurus cinereus; bat activity; bat diet; apple orchard; organic farming; pesticides; Michigan

\section{Introduction}

Use of synthetic pesticides in conventional agriculture not only causes health concerns, but also incurs social and environmental costs (Cleveland et al. 2006). Although pesticides are helpful in controlling injurious species, such compounds can have a negative impact on beneficial organisms (Morales 2002). In addition, regular application of synthetic pesticides can result in a community of insects more resistant to specific chemicals (Turgut et al. 2011) and a need to develop new substances or apply more of the old, thus increasing production costs (do Amarante et al. 2008). A growing concern of both consumers and farmers over the use of pesticides has led some growers to move from conventional to organic practices (Meisterling et al. 2009; Turgut et al. 2011). Organic management excludes the use of synthetic pesticides and fertilizers, fungicidal and insecticidal soaps, botanical insecticides, and sulfur and copper compounds (Holb et al. 2003; Peck et al. 2006).

Differences in farming practices between organic and conventional farms should lead to differences in their communities of insects in terms of number of individuals, taxonomic composition, or both (Letourneau and Goldstein 2001; Bengtsson et al. 2005; Miñarro et al. 2009; Padmavathy and Poyyamoli 2011; Mates et al., 2012). These presumed differences in insect communities should be reflected in the level of activity and diet of bats, the primary nocturnal predators on insects (Genghini et al. 2006; Braun de Torres 2011). In the United Kingdom, for example, Wickramasinghe et al.
(2003) claimed that organic farms provided islands of high-quality foraging habitat for insectivorous bats and proposed organic practices as a potential tool for increasing the numbers and kinds of bats in agricultural areas.

In this study, we tested the hypothesis that organic procedures affect the number and diversity of bats and insects in orchards that grow apples, an economically important crop in Canada and the United States (Ontario Ministry of Agriculture and Food 2007*; USDA $2012 *)$. We predicted that the abundance and diversity of both bats and insects would be greater at organic sites. Based on the presumed greater abundance of insects on organic farms, we also predicted that reproductively active adult female bats, which must bear the high energetic cost of pregnancy and lactation (Kurta et al. 1989, 1990), would be more common in organic orchards, relative to adult males and non-reproductive females, than at conventional sites. Finally, many species of bats are selective opportunists, generally concentrating on certain types of prey but often increasing consumption of locally abundant taxa (Fenton and Morris 1976; Murray and Kurta 2002). Consequently, we predicted that the diet of bats would vary between organic and conventional sites, reflecting the assumed differences in composition of the insect community.

\section{Study Area}

Our study took place in four organic and four conventional apple orchards in southern Michigan, within $200 \mathrm{~km}$ of Jackson $\left(41^{\circ} 51^{\prime}\right.$ to $43^{\circ} 1^{\prime} 48^{\prime \prime} \mathrm{N}, 83^{\circ} 40^{\prime} 12^{\prime \prime}$ to 
8451'36"W; Smith 2012). All orchards were in rural, agricultural areas, with corn and soy as the most common crops. The apple trees in the eight orchards were either small dwarf varieties (1-3 m in height) or semidwarf trees (3-5 $\mathrm{m}$ in height). Orchards varied in size from 5.7 to 24.3 ha, with a mean of 13.2 ha. Average distance between an orchard and the closest other orchard used in the study was $112 \mathrm{~km} \pm 10$ (SE). All fieldwork took place between 5 June and 13 August 2009 and between 18 May and 12 August 2010.

\section{Methods}

\section{Field and laboratory techniques}

To sample insects, we used a light trap (Model 2815A, BioQuip, Gardena, California), powered by a 12-volt battery. Light trapping occurred at only one orchard on any given night and coincided with mist netting for bats (see below). The trap was turned on $1 \mathrm{~h}$ before sunset and deactivated about $5 \mathrm{~h}$ later, immediately after the mist-netting system was dismantled. Captured insects were preserved in $70 \%$ ethanol for later counting and identification to order with the aid of a dissecting microscope.

Bats were captured using mist nets made from 50denier, braided nylon (Avinet, Dryden, New York). Netting systems were 6-9 $\mathrm{m}$ high and 6-12 $\mathrm{m}$ wide, depending on the size of available flight corridors. Mist netting was typically carried out 3-5 times a week, depending on weather, but in only one orchard on any given night. Netting began at sundown and continued for $4 \mathrm{~h}$. Ambient temperature was recorded at the beginning and end of mist netting. Each captured bat was identified to species, sexed, and classified as adult or juvenile, depending on fusion of the epiphyseal plates at the metacarpal-phalangeal joints (Anthony 1988). Females were further identified as non-reproductive, pregnant, lactating, or post-lactating based on body mass, abdominal palpation, and ability to express milk from the nipples (Racey 1988).

Fecal samples were collected from each captured bat by placing the animal in a paper lunch bag until defecation occurred. Fecal pellets were frozen for later examination, when each pellet was soaked in $95 \%$ ethanol and teased apart under a dissecting microscope. The resulting insect fragments were identified to order, and the percent volume of each order was estimated visually for each pellet (Whitaker 1988).

To complement mist netting, we used ultrasonic detectors to assess activity of bats. Each monitoring unit consisted of an ultrasonic detector (Anabat II, Titley Electronics, Ballina, Australia), a zero-crossings analysis interface module (ZCAIM), and a small battery (12-volt, $5 \mathrm{~A}$-h) housed in a protective case. A $5-\mathrm{cm}$ diameter opening was cut into the side of the case, and a piece of polyvinylchloride pipe in the shape of a flat U was attached (Smith 2012). When in use, the microphone of the detector rested inside the inner opening of the pipe. The detector sensed ultrasound produced by each bat, whereas the ZCAIM transformed the sound into a digital signal and recorded the frequencyversus-time structure of the call as a file on a compact flash card inside the ZCAIM. Detectors were calibrated against each other before use (Larson and Hayes 2000) with an ultrasonic distance-measuring device (Model 10065, Sonin, Charlotte, North Carolina).

Eight monitoring units were established, one at each orchard. Each unit was programmed to record from about 30 minutes before local sunset to about $30 \mathrm{~min}$ utes after local sunrise. During recording, the cases were positioned on a pole, about $6 \mathrm{~m}$ above the ground. After downloading files each week, we moved the unit to a new, randomly selected site in each orchard.

The number of files recorded per night was used as a measure of bat activity. If a particular monitoring unit did not function for the entire night, then all results from that night were discarded. Recorded calls were examined using Analook W software (version 3.3q, 2006, http://hoarybat.com) and assigned to one of four groups: Myotis spp., Eastern Red Bat (Lasiurus borealis), Hoary Bat (Lasiurus cinereus), or Big Brown Bat (Eptesicus fuscus) (Flaquer et al. 2007; Brooks 2009; Morris et al. 2010). Although a few calls categorized as Big Brown Bat may have been made by Silver-haired Bats (Lasionycteris noctivagans), the latter species is rare, representing less than $0.1 \%$ of bats that are mist netted in southern lower Michigan in summer (Winhold and Kurta 2008; Kurta 2010). No attempt was made to categorize sequences of calls with fewer than three individual pulses or consisting of pulses of low quality (Johnson et al. 2002; Francl 2008; Johnson and Gates 2008).

\section{Statistical analyses}

We focused our analysis on Big Brown Bats because they were the predominant species in the area. To determine differences in diet between the two types of orchards, we used two-sample independent $t$-tests. Chi-squared tests were used to examine differences in the composition of insects (by order) captured and differences in calls of bats recorded at the two types of orchards. In addition, chi-squared tests were used to analyze differences between the two types of orchards in terms of the proportion of reproductive versus nonreproductive female Big Brown Bats and male versus female adult Big Brown Bats. Both types of tests were conducted using VassarStats (Lowry 2008*).

A nested analysis of variance was used to detect differences between organic and conventional orchards in the number of acoustic records, bats netted, and insects captured. Only orders of insects that contributed at least $5 \%$ of the total amount captured were included in the comparison. Minimum ambient temperature was used as a covariate in these three analyses, because temperature can affect the number and diversity of insects that are active (e.g., see Ciechanowski et al. 2007; Le Lann et al. 2011). To obtain normally distributed data, we added 1 to the raw counts obtained from 
acoustic monitoring, mist netting, and light trapping and applied a logarithmic transformation before performing statistical analyses. Analyses were performed primarily with Systat 10.2 (Systat Software, Inc., Richmond, California) or Excel (Microsoft, Redmond, Washington).

A nested analysis of variance was also used to compare the percent volume of various orders of insects found in the diet of bats from organic and conventional orchards. The percent volume represented by each insect order in the fecal pellets produced by each bat was converted to a proportion, and the square root of each proportion was arcsine-transformed to attain normal distribution of the data (Zar 1999). Only orders that contributed at least $5 \%$ of the total volume were included in these comparisons.

Different practices in conventional and organic orchards could affect not only the overall level of activity of bats and insects, but also the structure of the local communities (Bengtsson et al. 2005; Macfadyen et al. 2009; Power and Stout 2011). Consequently, we also calculated taxonomic diversity, using the level of species or genus for the bats and order for the insects that were captured or identified in the feces. As a measure of diversity, we used Simpson's index, which is equal to $1-\left[\sum n_{\mathrm{i}}\left(n_{\mathrm{i}}-1\right)\right] / N(N-1)$, where $n_{\mathrm{i}}$ is the number of individuals in each taxonomic group and $N$ is the total number of captured species or orders (Brower and Zar 1984). We calculated diversity for each orchard and compared mean diversity of organic and conventional orchards using a standard $t$-test. All data are presented as the mean and standard error (SE), and alpha was set to 0.05 for all statistical tests.

\section{Results}

Over the 2 years of our study, we trapped insects on 36 nights in organic sites and 38 nights in conventional orchards for a total of 5233 insects $(138 \pm 22$ insects/ night) from the organic orchards and 4179 insects (116 \pm 20 insects/night) from conventional orchards. There was no significant difference between the two types of orchards in number of insects trapped per night $\left(F_{1,6}\right.$ $=0.03, P=0.87)$. Five orders of insects - Coleoptera (beetles), Diptera (flies), Hemiptera (true bugs), Lepidoptera (moths), and Trichoptera (caddisflies) accounted for $96 \%$ of the insects captured. There was no significant difference between the two types of orchards in numbers of insects by order captured per night (all $F_{1.6} \leq 0.54, P \geq 0.49$; Table 1). The mean diversity at the ordinal level was also not significantly different $\left(t_{32}=1.95 ; P=0.13\right)$ : organic locations $(0.71$ $\pm 0.03)$ and conventional orchards $(0.76 \pm 0.00)$.

Beetles were the most abundant order of insects in both types of orchard, representing $40 \%$ and $31 \%$ of captures in organic and conventional orchards, respectively (Table 1). The next most common order at organic sites was moths $(21 \%)$, but at conventional orchards flies were the second most abundant order (23\%). A preliminary chi-squared test indicated significant heterogeneity in the composition of the five most common orders of insects among both the organic $\left(\chi^{2}{ }_{12}=\right.$ 293.57; $P<0.001)$ and conventional $\left(\chi_{12}^{2}=615.74\right.$; $P<0.001)$ orchards, which precluded a statistically valid comparison of the overall composition of insects between types of orchards using chi squared.

Mist netting was carried out on 37 nights in organic and 38 nights in conventional apple orchards and yielded 136 bats. Of these bats, 54 (39.7\%) were netted in organic orchards $(1.5 \pm 0.4$ captures/night $)$, and $82(60.3 \%)$ in conventional orchards $(2.2 \pm 0.6$ captures/night). The difference in number of captures per night between organic and conventional orchards was not significant $\left(F_{1.6}=0.26, P=0.63\right)$.

We caught 131 Big Brown Bats and 5 Eastern Red Bats - the two most common species in the region (Winhold and Kurta 2008; Smith 2012) - and we focus our analyses on the more-abundant Big Brown Bat. They consisted of 44 adult females, 27 juvenile females, 32 adult males, and 28 juvenile males. Of the adult females, 14 reproductive (six pregnant, three lac-

TABLE 1. Average number (\%) of insects of the five most abundant orders captured per night at each orchard in southern Michigan. Orders contributing less than $5 \%$ of the total number of insects trapped in both types of orchard were not included (Smith, 2012); thus, row percentages do not total $100 \%$.

\begin{tabular}{|c|c|c|c|c|c|c|}
\hline$\overline{\text { Orchard }}$ & Lepidoptera & Coleoptera & Diptera & Hemiptera & Trichoptera & Total \\
\hline \multicolumn{7}{|l|}{ Orchard } \\
\hline AlMar E & $3.6(17.4)$ & $8.9(42.7)$ & $5.3(25.2)$ & $0.5(2.4)$ & $2.5(12.1)$ & $20.8(99.8)$ \\
\hline AlMar SE & $6.1(18.7)$ & $11.8(36.0)$ & $6.2(19.0)$ & $4.3(13.2)$ & $4.1(12.7)$ & $32.5(99.6)$ \\
\hline Apple Schram & $11.4(32.1)$ & $15.2(42.7)$ & $3.8(10.8)$ & $1.9(5.5)$ & $2.9(8.3)$ & $35.2(99.4)$ \\
\hline Country Mill & $3.4(12.8)$ & $10.9(40.6)$ & $5.3(19.6)$ & $2.8(10.5)$ & 4.3 (15.9) & $26.7(99.4)$ \\
\hline Total & $24.6(21.2)$ & $46.8(40.3)$ & $20.6(17.7)$ & $9.6(8.3)$ & $13.9(12.0)$ & $115.5(99.5)$ \\
\hline \multicolumn{7}{|l|}{ Conventional } \\
\hline Erwin & $5.1(18.4)$ & $9.8(35.6)$ & $4.4(15.9)$ & $1.3(4.6)$ & $6.8(24.6)$ & $27.4(99.1)$ \\
\hline Spicer & $4.6(25.3)$ & $5.9(32.3)$ & $3.8(20.7)$ & $1.9(10.6)$ & $1.9(10.5)$ & $18.1(99.4)$ \\
\hline Swinderman N & $3.3(5.0)$ & $18.5(27.9)$ & $19.6(29.5)$ & $2.7(4.1)$ & $20.2(30.6)$ & $64.3(97.1)$ \\
\hline Swinderman S & $2.9(11.3)$ & $8.9(34.8)$ & $4.1(16.1)$ & $1.2(4.7)$ & $1.2(4.7)$ & $18.3(71.6)$ \\
\hline Total & $15.9(11.6)$ & $43.1(31.3)$ & $31.8(23.1)$ & $7.1(5.2)$ & $30.1(21.8)$ & $128.0(93.0)$ \\
\hline Overall average & $20.1(15.9)$ & $44.9(35.3)$ & $26.4(20.7)$ & $8.3(6.5)$ & $22.2(17.5)$ & $121.9(95.9)$ \\
\hline
\end{tabular}


tating, and five post-lactating) and 3 non-reproductive bats were netted in organic orchards and 21 reproductive (4 pregnant, 13 lactating, and 4 post-lactating) and 6 non-reproductive bats were netted in conventional orchards. The difference in proportion of reproductive and non-reproductive female Big Brown Bats between organic and conventional orchards was not significant $\left(\chi_{1}^{2}=0.0 ; P=1\right)$. The ratios of male to female adults (15:17 in organic orchards and 17:27 in conventional orchards) were also not significantly different $\left(\chi_{1}^{2}=0.23 ; P=0.63\right)$.

Acoustic monitoring records for the combined field seasons consisted of 25945 files containing sounds made by bats during 569 detector-nights; a detectornight was defined as a complete night of recording, from before sunset to after sunrise, by one detector. Of these files, 10217 were recorded on 279 detector-nights in the four organic orchards, whereas 15728 were recorded on 329 detector-nights in the four conventional orchards. Although more files per night were recorded in conventional orchards $(51 \pm 14$ files/night) than in organic orchards ( $37 \pm 8$ files/night), the difference was not significant $\left(F_{1,6}=0.20, P=0.67\right)$.

We assigned $11045(43 \%)$ of the recordings to genus or species. Most calls from all orchards were produced by Big Brown Bats (59\%), followed by Hoary Bats (28\%), Eastern Red Bats (13\%), and Myotis spp. $(<1 \%$; Table 2). The mean diversity of bats in organic orchards $(0.53 \pm 0.02)$ was not statistically different $\left(t_{6}=0.78\right.$; $P=0.23)$ from that in conventional orchards $(0.57 \pm$ 0.05 ). A preliminary chi-squared test indicated considerable heterogeneity in taxonomic composition of the calls of bats in both organic $\left(\chi_{9}^{2}=109 ; P<0.001\right)$ and conventional $\left(\chi_{9}^{2}=424 ; P<0.001\right)$ orchards, which prevented a statistically meaningful comparison of overall composition between the two types of orchards using chi squared.

We examined 131 fecal pellets from Big Brown Bats and found that, overall, their diet included five orders of insects: Coleoptera (79.3\% by volume), Diptera $(13.2 \%)$, Lepidoptera $(0.6 \%)$, Hemiptera $(0.7 \%)$, and Hymenoptera $(0.7 \%$; Table 3$)$. Mean diversity of the diet at the ordinal level was not significantly different $\left(t_{6}=0.95 ; P=0.19\right)$ between organic locations $(0.30 \pm 0.04)$ and conventional orchards $(0.36 \pm 0.05)$. There were no significant differences between organic and conventional orchards in percentage volume of the two most common orders: Coleoptera $\left(F_{1,6}=0.21, P\right.$ $=0.66)$ and Diptera $\left(F_{1,6}=0.01, P=0.92\right)$.

TABLE 2. Numbers (and \%) of bats identified from recordings by ultrasonic detectors in four organic and four conventional apple orchards in southern Michigan.

\begin{tabular}{lccc}
\hline \hline Species & Organic orchard & Conventional orchard & Total \\
\hline Big Brown Bat & $2943(63.7)$ & $3554(55.3)$ & $6497(58.8)$ \\
Hoary Bat & $1030(22.3)$ & $2030(31.6)$ & $3060(27.7)$ \\
Eastern Red Bat & $631(13.7)$ & $826(12.9)$ & $1457(13.2)$ \\
Myotis spp. & $15(0.3)$ & $16(0.3)$ & $31(0.3)$ \\
Total & 4619 & 6426 & 11045 \\
\hline \hline
\end{tabular}

Note: Big Brown Bat, Eptesicus fuscus; Hoary Bat, Lasiurus cinereus; Eastern Red Bat, L. borealis.

TABLE 3. Percent volume of insects, by order, consumed by Big Brown Bats, Eptesicus fuscus, in four organic and four conventional apple orchards in southern Michigan based on fecal pellet analysis. Columns may not add to 100 because of rounding errors.

\begin{tabular}{lccc}
\hline \hline & & Volume consumed (\%) & \\
\cline { 2 - 4 } Insect order & $\begin{array}{c}\text { Organic orchard } \\
(n=52 \text { bats })\end{array}$ & $\begin{array}{c}\text { Conventional orchard } \\
(n=79 \text { bats })\end{array}$ & $(n=131$ bats $)$ \\
\hline Coleoptera & 79.3 & 78.0 & 78.6 \\
Diptera & 13.2 & 13.9 & 13.5 \\
Lepidoptera & 0.6 & 1.3 & 1.0 \\
Hemiptera & 0.7 & 1.1 & 0.9 \\
Hymenoptera & 0.7 & 0.2 & 0.5 \\
Unknown & 5.5 & 4.5 & 5.0 \\
\hline \hline
\end{tabular}

\section{Discussion}

We predicted that adult female bats would be more common in organic orchards than conventional ones, but the sex ratio of adult Big Brown Bats did not differ between types of orchard, nor did the ratio of reproductive to non-reproductive adult females. Although our predictions were not upheld, this is not surprising because they were predicated on an assumed difference in the insect community between organic and conventional orchards. However, light trapping revealed that total abundance and diversity of insects, as well as the abundance of the five most common orders of insects, did not differ between types of orchards (Table 1). Availability of prey at the ordinal level, therefore, was 
similar in organic and conventional apple orchards, suggesting no reason for energetically stressed females to favour one type of orchard over the other.

To date, only one quantitative study has been published concerning activity of bats on organic and conventional farms of any type (Wickramasinghe et al. 2003). The authors compared bat activity on organic and conventional farms in England and Wales, using acoustic monitoring and captures via mist net, as we did in Michigan. However, they reported that bat activity was $61 \%$ greater on organic than conventional farms. Also, in a companion study, Wickramasinghe et al. (2004) detected a significantly greater number of insects belonging to five families at organic locations, although pairwise statistical comparisons of 13 other families showed no differences between organic and conventional sites.

However, the farms in the studies by Wickramasinghe et al. $(2003,2004)$ differed greatly from ours. Fifty-four percent of the farms in Wickramasinghe et al. (2004) were classified as livestock operations and another $41 \%$ were mixed, involving both livestock and unspecified crops. The farming practices and potential chemicals used in pastures and orchards differed. For example, avermectin, an antihelminthic drug often used with cattle and sheep on conventional farms, can reduce the number of invertebrates using ungulate feces, i.e., dung beetles (Scarabaeidae and Geotrupidae; Strong 1992), which are commonly eaten by some British bats (Wickramasinghe et al. 2004). Furthermore, Wickramasinghe et al. (2003, 2004) sampled bats and insects in various habitats, and most differences they reported involved pastoral and aquatic habitats; these habitats generally were not present in the orchards we studied (Smith 2012). Finally, the average size of their farms (about 51 ha; Wickramasinghe et al. 2003) was more than double the area of our largest orchard (24 ha).

Wickramasinghe et al. (2003) proposed organic practices as a potential conservation strategy for increasing the numbers and kinds of bats in agricultural regions. However, we were unable to document differences in the number, richness, and diversity of bats; in the dietary composition of the bats; in overall activity and diversity of insects at the ordinal level; or in the abundance of particular orders of insects. The fact that taxonomic composition of the captured insects and the acoustic recordings of bats were not homogenous among either conventional or organic orchards suggests that factors other than farming practices, such as differing patterns of land use and habitats in the surrounding landscape, were more important in determining the types of insects and bats found in apple orchards typical of southern Michigan.

Apple orchards in other parts of North America, though, can be as large as 1200 ha (Washington Apple Commission $2010^{*}$ ), and a suggested area of further study is to examine the relation between size of orchard and potential differences in their associated commu- nities of insects and bats. Large size might insulate the interior of organic orchards from surrounding conventional farms and potentially allow development of disparate communities, as found by Wickramasinghe et al. (2003, 2004). In addition, recent advances in molecular techniques, such as high-throughput sequencing (Bohmann et al. 2011; Razgour et al. 2011), now allow biologists to sequence the DNA of every item of prey in the fecal material produced by a bat. Although many sequences obtained in this manner cannot be identified to species or other taxonomic level below order, use of molecular operational taxonomic units offers a promising way of comparing diversity of prey in different types of orchards at a more detailed level than visual analysis (Chesters et al. 2013; Rolfe et al. in press). Further research, concerning organic practices and bats is warranted, because bats are experiencing unprecedented mortality in North America from wind turbines (Kunz et al. 2007) and white-nose syndrome (Turner et al. 2011), and determining factors that promote the conservation of these flying mammals is essential to their long-term survival.

\section{Acknowledgements}

We thank the farmers and their assistants for providing access to their orchards: J. Bush (Apple Schram Orchard), B. Erwin (Erwin Orchard), J. Koan (AlMar Orchard), A. Spicer (Spicer Orchard), J. Swinderman (Apple Wood Orchard), and S. Tennes (Country Mill Orchard). S. Francoeur and C. Rockey provided advice on statistics and acoustic monitoring, respectively. We thank Mckinley Ophelia for keeping BLL company on many long nights in the orchards when everyone else was asleep. A. Rolfe and J. Veilleux provided helpful comments on the manuscript. Financial support was provided by a grant from the Organic Farming Research Foundation to S. Tennes; a Faculty Research Fellowship from Eastern Michigan University awarded to AK; and a Hellwig Research Award given to BLL by the Department of Biology at Eastern Michigan University.

\section{Documents Cited (marked * in text)}

Lowry, R. 2008. VassarStats: website for statistical computation. Vassar College, Poughkeepsie, New York. Accessed 3 November 2013. http://faculty.vassar.edu/lowry/Vassar Stats.html.

Ontario Ministry of Agriculture and Food. 2007. Marketed production of apples by province, Canada, 1995 to 2005 . Ontario Ministry of Agriculture and Food, Toronto, Ontario, Canada. Accessed 25 October 2013. http://www.oma fra.gov.on.ca/english/stats/hort/glance/table4.htm.

USDA (United States Department of Agriculture). 2012. U.S. apple statistics. USDA, Economic Research Service, Washington, D.C., USA. Accessed 3 November 2013. http://usda.mannlib.cornell.edu/MannUsda/viewDocument Info.do?documentID $=1825$

Washington Apple Commission. 2010. Washington apple history. Washington Apple Commission, Wenatchee, Washington, USA. Accessed 26 October 2013. http://www.best apples.com/facts/facts_washington.aspx. 


\section{Literature Cited}

Anthony, E. L. P. 1988. Age determination in bats. Pages 47-58 in Ecological and Behavioral Methods for the Study of Bats. Edited by T. H. Kunz. Smithsonian Institution Press, Washington, D.C., USA.

Bengtsson, J., J. Ahnström, and A. Weibull. 2005. The effects of organic agriculture on biodiversity and abundance: a meta analysis. Journal of Applied Ecology 42: 261-269.

Bohmann, K., A. Monadjem, C. L. Noer, M. Rasmussen, M. R. K. Zeale, E. Clare, G. Jones, E. Willerslev, and T. G. P. Gilbert. 2011. Molecular diet analysis of two African free-tailed bats (Molossidae) using high throughput sequencing. PLoS One 6: e21441.

Braun de Torres, E. 2011. Pecan orchards welcome bats and bats return the favor. Bats 29: 2-4.

Brooks, R. T. 2009. Habitat-associated and temporal patterns of bat activity in a diverse forest landscape of southern New England, USA. Biodiversity and Conservation 18: 529-545.

Brower, J. E., and J. H. Zar. 1984. Field and Laboratory Methods for General Ecology. Second edition. Wm. C. Brown, Dubuque, Iowa, USA. 226 pages.

Chesters, D., F. Yu, H. X. Cao, Q. Y. Dai, Q. T. Wu, W. Shi, W. Zheng, and C. D. Qhu. 2013. Heuristic optimization for global species clustering of DNA sequence data for multiple loci. Methods in Ecology and Evolution 4: 961970.

Ciechanowski, M., T. Zajac, A. Bilas, and R. Dunajski. 2007. Spatiotemporal variation in activity of bat species differing in hunting tactics: effects of weather, moonlight, food abundance, and structural clutter. Canadian Journal of Zoology 85: 1249-1263.

Cleveland, C. J., M. Betke, P. Federico, J. D. Frank, T. G. Hallam, J. Horn, J. D. Lopez, Jr., G. F. McCracken, R. A. Medellin, A. Moreno-Valdez, C. G. Sansone, J. K. Westbrook, and T. H. Kunz. 2006. Economic value of pest control service provided by Brazilian free-tailed bats in south-central Texas. Frontiers in Ecology and the Environment 4: 238-243.

do Amarante, C. V., C. A. Steffens, A. L. Mafra, and J. A. Albuquerque. 2008. Yield and fruit quality of apple from conventional and organic production systems. Pesquisa Agropecuária Brasileira 43: 333-340.

Fenton, M. B., and G. K. Morris. 1976. Opportunistic feeding by desert bats, Myotis spp. Canadian Journal of Zoology 54: 526-530.

Flaquer, C., I. Torre, and A. Arrizabalaga. 2007. Comparison of sampling methods for inventory of bat communities. Journal of Mammalogy 88: 526-533.

Francl, K. E. 2008. Summer bat activity at woodland seasonal pools in the northern Great Lakes region. Wetlands 28: 117-124.

Genghini, M., S. Gellini, and M. Gustin. 2006. Organic and integrated agriculture: the effects on bird communities on orchard farms in northern Italy. Biodiversity and Conservation 15: 3077-3094

Holb, I. J., P. F. de Jong, and B. Heijne. 2003. Efficacy and phylotoxicity of lime sulfur in organic apple production. Annals of Applied Biology 142: 225-233.

Johnson, J. B., and J. E. Gates. 2008. Bats of Assateague Island National Seashore, Maryland. American Midland Naturalist 160: 160-170.
Johnson, J. B., M. A. Menzel, J. W. Edwards, and W. M. Ford. 2002. A comparison of 2 acoustical bat survey techniques. Wildlife Society Bulletin 30: 931-936.

Kunz, T. H., E. B. Arnett, W. P. Erickson, A. R. Hoar, G. D. Johnson, R. P. Larkin, M. D. Strickland, R. W. Thresher, and M. D. Tuttle. 2007. Ecological impacts of wind energy development on bats: questions, research needs, and hypotheses. Frontiers in Ecology and the Environment 5: 315-324.

Kurta, A. 2010. Reproductive timing, distribution, and sex ratios of tree bats in Lower Michigan. Journal of Mammalogy 91: 586-592.

Kurta, A., G. P. Bell, K. A. Nagy, and T. H. Kunz. 1989. Energetics of pregnancy and lactation in free-ranging little brown bats, Myotis lucifugus. Physiological Zoology 62: 804-818.

Kurta, A., T. H. Kunz, and K. A. Nagy. 1990. Energetics and water flux of free-ranging Big Brown Bats, Eptesicus fuscus, during pregnancy and lactation. Journal of Mammalogy 71: 59-65.

Larson, D. J., and J. P. Hayes. 2000. Variability in sensitivity of Anabat II bat detectors and a method of calibration. Acta Chiropterologica 2: 209-213.

Le Lann, C., O. Roux, N. Serain, J. J. M. Van Alphen, P. Vernon, and J. Van Baaren. 2011. Thermal tolerance of sympatric hymenopteran parasitoid species: does it match seasonal activity? Physiological Entomology 36: 21-28.

Letourneau, D. K., and B. Goldstein. 2001. Pest damage and arthropod community structure in organic vs. conventional tomato production in California. Journal of Applied Ecology 38: 557-570.

Macfadyen, S., R. Gibson, A. Polaszek, R. J. Morris, P. G. Craze, R. Planqué, W. O. C. Symondson, and J. Memmott. 2009. Do differences in food web structure between organic and conventional farms affect the ecosystem service of pest control? Ecology Letters 12: 229-238.

Mates, S. G., I. Perfecto, and C. Badgely. 2012. Parasitoid wasp diversity in apple orchards along a pest-management gradient. Agriculture, Ecosystems, and Environment 156: $82-88$.

Meisterling, K., C. Samaras, and V. Schweizer. 2009. Decisions to reduce greenhouse gases from agriculture and product transport: LCA case study of organic and conventional wheat. Journal of Cleaner Production 17: 222-230.

Miñarro, M., X. Espadaler, V. X. Melero, and V. V. SuarezAlvarez. 2009. Organic versus conventional management in an apple orchard: effects of fertilization and tree-row management on ground-dwelling predaceous arthropods. Agricultural and Forest Entomology 11: 133-142.

Morales, H. 2002. Pest management in traditional tropical agroecosystems: lessons for pest prevention research and extension. Integrated Pest Management Review 7: 145163.

Morris, A. D., D. A. Miller, and M. C. Kalcounis-Rüeppell. 2010. Use of forest edges by bats in a managed pine forest landscape. Journal of Wildlife Management 74: 26-34.

Murray, S., and A. Kurta. 2002. Spatial and temporal variation in diet. Pages 182-192 in The Indiana Bat: Biology and Management of an Endangered Species. Edited by A. Kurta and J. Kennedy. Bat Conservation International, Austin, Texas, USA. 253 pages

Padmavathy, A., and G. Poyyamoli. 2011. Enumeration of arthropod density in context to plant diversity and agri- 
cultural (organic and conventional) management systems. International Journal of Agricultural Research 6: 805-818.

Peck, G. M., P. K. Andrews, J. P. Reganold, and J. K. Fellman. 2006. Apple orchard productivity and fruit quality under organic, conventional, and integrated management. Horticultural Science 41: 99-107.

Power, E. F., and J. C. Stout. 2011. Organic dairy farming: impacts on insect-flower interaction networks and pollination. Journal of Applied Ecology 48: 561-569.

Racey, P. A. 1988. Reproductive assessment in bats. Pages 31-45 in Ecological and Behavioral Methods for the Study of Bats. Edited by T. H. Kunz. Smithsonian Institution Press, Washington, D.C., USA.

Razgour, O., E. L. Clare, M. R. K. Zeale, J. Hanmer, I. B. Schnell, M. Rasmussen, T. P. Gilbert, and G. Jones. 2011. High-throughput sequencing offers insight into mechanisms of resource partitioning in cryptic bat species. Ecology and Evolution 4: 556-570.

Rolfe, A. K., A. Kurta, and D. L. Clemans. Species-level analysis of diets of two mormoopid bats from Puerto Rico. Journal of Mammalogy, in press.

Smith, B. L. 2012. Activity and diet of bats in apple orchards of southern Michigan. M.Sc. Thesis, Eastern Michigan University, Ypsilanti, Michigan, USA.

Strong, L. 1992. Avermectins: a review of their impact on insects in cattle dung. Bulletin of Entomological Research 82: 265-274.

Turgut, C., H. Ornek, and T. J. Cutright. 2011. Determination of pesticide residues in Turkey's table grapes: the effect of integrated pest management, organic farming, and conventional farming. Environmental Monitoring and Assessment 173: 315-323.

Turner, G. G., D. Reeder, and J. T. H. Coleman. 2011. A five-year assessment of mortality and geographic spread of white-nose syndrome in North American bats, with a look at the future. Bat Research News 52: 13-27.

Whitaker, Jr., J. O. 1988. Food habits analysis of insectivorous bats. Pages 171-189 in Ecological and Behavioral Methods for the Study of Bats. Edited by T.H. Kunz. Smithsonian Institution Press, Washington, D.C., USA.

Wickramasinghe, L. P., S. Harris, G. Jones, and N. Vaughan. 2003. Bat activity and species richness on organic and conventional farms: impact of agricultural intensification. Journal of Applied Ecology 40: 984-993.

Wickramasinghe, L. P., S. Harris, G. Jones, and N. V. Jennings. 2004. Abundance and species richness of nocturnal insects on organic and conventional farms: effects of agricultural intensification on bat foraging. Conservation Biology 18: 1283-1292.

Winhold, L., and A. Kurta. 2008. Netting surveys for bats in the Northeast: differences associated with habitat, duration of netting, and use of consecutive nights. Northeastern Naturalist 15: 263-274.

Zar, J. H. 1999. Biostatical Analysis. Fourth edition. Prentice Hall, Upper Saddle River, New Jersey, USA.

Received 8 November 2013

Accepted 28 January 2014 